\title{
Aggressive Angiomyxoma of Vulva
}

\section{Iyengar RS, Padmasri R}

Department of Obstetrics and Gynaecology,

Sapthagiri Institute of Medical Sciences and Research Centre,Bangalore, India.

\section{Dear Editor,}

Aggressive angiomyxoma (AA) is a rare slow growing mesenchymal tumour that preferentially involves the vulvovaginal, pelvic or perineal regions. ${ }^{1}$ In 1983 Steeper and Rosai coined the term AA. It is called aggressivedue to itsfrequent local recurrences and infiltrative behaviour. ${ }^{2}$ In women, they occur more commonly in reproductive age and reach a large size of usually more than $10 \mathrm{~cm}$. The differential diagnosis of this unusual tumour includes myxoma, myxoid liposarcoma, sarcoma botryoides, myxoid variant of malignant fibrous histiocytoma, nerve sheath myxoma, and other soft tissue tumours with secondary myxoid changes. ${ }^{3}$ Histological examination is characteristic of the tumour with its vascular element and stellate cells. Immunohistochemistry for oestrogen and progesterone receptors, which are positive in more than $90 \%$ of the tumour cells, is helpful in confirming diagnosis. ${ }^{4}$

A forty-year- parous woman with history of three full term home deliveries presented with a vulval growth since four weeks. The mass was initially pea sized and had grown rapidly to present size of $13 \times 10 \times 5 \mathrm{~cm}$. The neoplasm arose from the left labia majora with a broad pedicle of $1.5 \mathrm{~cm}$ width and $4 \mathrm{~cm}$ length. It was soft in consistency,non-tender and the overlying skin was normal. Abdominopelvic examination was normal. A clinical diagnosis of pedunculated lipoma was made. The growth was excised by cutting the pedicle at the base. Cut surface of the tumour was soft with yellowish gelatinous appearance. Multiple

\section{CORRESPONDENCE}

\section{Dr Rupa S Iyengar}

Department of Obstetrics and Gynaecology,

Sapthagiri Institute of Medical Sciences and Research Centre, Bangalore, India.

Email: rupasiyengar@gmail.com

Phone: +919844046530 sections on microscopy revealed a neoplasm composed of scattered spindle to stellate shaped cells with ill-defined cytoplasm. There was presence of thin and thick vascular channels in the myxoid stroma along with collagen fibres and perivascular lymphoid aggregates. Mitotic figures were absent. This microscopic appearance led to the diagnosis of aggressive angiomyxoma of the vulva (Figure 1). Patient has been tumour free ather six monthly follow up.

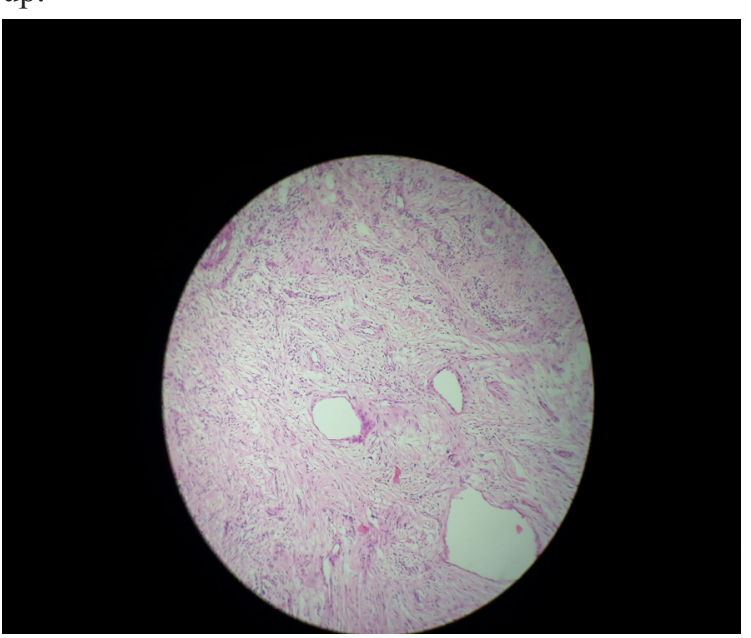

Figure 1. Microscopic picture stained with haematoxylin and eosin stain shows vascular channels dispersed in the myxoid stroma.

Study of literature reports less than 250 cases of angiomyxomas. Of these, the vulval tumours tend to be occasional. Though more commonly seen in

The papers in this journal are published under the terms of the Creative Commons Attribution License. Users are allowed to read, download, copy, distribute, print, search, or link to the full texts of the articles in this journal without asking prior permission from the publisher or the author. 
women, a few cases has been reported in men. The male to female ratio of occurrence being one to six. ${ }^{5} \mathrm{~A}$ should be considered in differential diagnosis of tumours seen in men, in analogous regions such as inguinoscrotal, spermatic cord and perineum. It can occur in children of both sexes. The youngest person detected with this tumour being an 11-yearold boy.They usually present as a painless cyst or swelling in vulval or pelvic region. Pelvic region lesions if involving urinary bladder or uterus can cause dysmenorrhoea, dyspareunia, bladder and bowel symptoms. Clinically they are often mistaken for Bartholin's cyst, lipoma, vulval abscess, Gartner's cyst, vaginal prolapse, vaginal cyst, levator hernia or hernia of canal of Nuck. So far only two tumours with metastasis to lungs have been reported, one of them being fatal. ${ }^{6}$ The tumour is believed to arise from the primitive cells normally found in the female genital tract. Magnetic resonance imaging (MRI) is the gold standard for differential diagnosis of these lesions. Aggressive angiomyxomas have a characteristic MRI appearance. Typically, an aggressive angiomyxoma will appear as high signal intensity on T2-weighted MR images with heterogeneous contrast enhancement and awhorled pattern of signal intensity. MR imaging can also demonstrate unusual growth patterns of these tumours, such as translevator extension and growth around pelvic organs. This allows the surgeon to plan the best surgical route, such as a perineal or abdominal approach. The high signal intensity on MRI is due to the loose myxoid matrix and high water content of angiomyxoma. ${ }^{7}$ The contrast enhancement is due to the inherent vascular nature of the tumour. This enhancement is absent in a bartholin's abscess. Myomas have low signal intensity on T2 weighted images with uniform enhancement. Lipomas show signal intensity dropout on fat suppressed images. Endometriomas show high signal intensity on $\mathrm{T} 1$ weighted images with shading due to presence of cyclical deposition of blood. Malignant tumours show high signal intensity on $\mathrm{T} 1$ weighted images with infiltration whereas AA shows only displacement of surrounding structures. None of the tumours demonstrates a whorled T2 high signal intensity image. Our patient did not undergo a radiological study, as clinical diagnosis was of a lipoma. Histologically angiomyofibroblastoma shares many features with aggressive angiomyxoma. The presence of a sharply circumscribed border, and plump epithelioid tumour cells arranged in a predominantly perivascular distribution usually allow distinction from aggressive angiomyxoma. Superficial angiomyxoma can be distinguished from aggressive angiomyxoma and angiomyofibroblastoma by the multinodular growth, abundant stromal mucin, low cellularity, and lack of perivascular accentuation of stromal cells. ${ }^{5} \mathrm{AA}$ has thick-walled vessels, which are less numerous than the thin-walled vessels in angiomyofibroblastoma. There is no specific immunohistochemical marker for AA but the stromal cells show characteristic immunopositivity for oestrogen and progesterone receptors,vimentin, desmin, muscle-specific actin, CD34 and CD44. All are invariably negative for S-100, CEA and keratin. Genetically, AA demonstrates chromosomal translocation at level of $12 q$ involving high mobility group A (HMGA2) gene. Most mesenchymal lesions, which mimic AA, are negative for HMGA2 immunohistochemistry. Hence when in doubt it is useful in primary diagnosis. It is also useful in evaluating margins and in identifying foci of residual or recurrent tumour. ${ }^{8}$ Radical surgery with wide margin of excision is treatment of choice. Risk of recurrence tends to be the same for those with positive margins and those with negative margins. When fertility needs to be preserved and surgical access is difficult, incomplete removal is acceptable. Several reported attempts using chemotherapy and radiotherapy as part of the treatment for AA have been disappointing, probably due to the low mitotic activity and growth fraction of cells. The hormone dependency of AA assignified by the presence of oestrogen and progesterone receptorsis utilized inmanaging cases of AA, either primary or recurrent, which are not amenable to surgical excision. Gonadotropin releasing hormone $(\mathrm{GnRH})$ agonists, raloxifene and tamoxifen are used in these cases of AA. These agents may also be used to effect a reduction in size, so that the radicality of surgery may be reduced. ${ }^{9}$ In one case the drug, triptorelin, was given for three months post operative to prevent recurrence. Angiographic embolization may also help in subsequent resection by shrinking the tumour as well as making it easier to identify it from surrounding normal tissues..$^{10} \mathrm{As}$ late recurrences are common, all patients need to be counselled about the need for long-term follow-up.

It is essential to be aware of the differential diagnosis of vulval tumours before doing a definitive therapeutic surgery. Radiologic studies and pathologic evaluation of the mass will aid in planning the appropriate treatment and will avoid missing out rare tumours. Close and long-term follow up of these patients should be emphasised due to high rate of recurrence.

\section{REFERENCES}

1. Elkattah R, Sarkodie O, Otteno H, Fletcher A.Aggressive angiomyxoma of the vulva: a précis for primary care providers. Obstet Gynecol. 2013;18:3725. 
2. Steeper TA, Rosai J. Aggressive angiomyxoma of the female pelvis and perineum: report of nine cases of a distinctive type of gynaecologic soft-tissue neoplasm. Am J Surg Pathol. 1983;7:463-75.

3. Behranwala A, Thomas JM. Aggressive angiomyxoma: a distinct clinical entity. Eur J Surg Oncol. 2003;29:559-63.

4. Sutton BJ, Laudadio J. Aggressive angiomyxoma. Arch Pathol Lab Med. 2012;136(2):217-21.

5. Sun NX, Li W. Aggressive angiomyxoma of the vulva: case report and literature review. J Int Med Res. 2010;38:1547.

6. Blandamura S, Cruz J, Faure Vergara L, Machado Puerto I, Ninfo V. Aggressive angiomyxoma: a second case of metastasis with patient's death. Hum Pathol. 2003;34:1072-4.
7. Sinha R, Verma R. Case 106: aggressive angiomyxoma. Radiology. 2007;242(2):626-7.

8. McCluggage WG, Connolly L, McBride HA. HMGA2 is a sensitive but not specific immunohistochemical marker of vulvovaginal aggressive angiomyxoma. Am J Surg Pathol. 2010;34(7):1037-42.

9. Vella R, Calleri D. Superficial angiomyxoma of the epidiymis Presentation of a new case and clinical considerations. Minerva Urol Nefrol. 2000;52(2):77-9.

10. Magtibay PM, Salmon Z, Keeney GL, Podratz KC. Aggressive angiomyxoma of the female pelvis and perineum: a case series. Int J Gynecol Cancer. 2006;16:396-401. 